\title{
RESECTION OF A SOLITARY PULMONARY ARTERIOVENOUS MALFORMATION BY VIDEO-ASSISTED THORACIC SURGERY
}

\author{
Roy T. Temes, MD, Pathmaja Paramsothy, BA, Santiago A. Endara, MD, Jorge A. Wernly, MD, Albuquerque, NM
}

Pulmonary arteriovenous malformation (PAVM) is an unusual tumor of the lung. It produces direct connections between pulmonary arterial and venous vessels, resulting in right-to-left shunts. Surgical resection offers definitive cure, but transcatheter ablation is used more often because of lower morbidity and mortality rates. The advent of minimally invasive surgical techniques offers the advantage of both treatments: definitive therapy with minimal morbidity and mortality rates. We report a case of this unusual tumor successfully treated with video-assisted thoracoscopic resection (VATS).

Clinical summary. A 37-year-old man had visual disturbances and dizziness. He also complained of cough, shortness of breath, and decreased exercise tolerance. A magnetic resonance image of the brain showed an occipital infarct. A chest radiograph showed a right lower lobe density. A computed tomographic (CT) scan of the thorax revealed a $4-\mathrm{cm}$ welldefined mass in the right lower lobe of the lung supplied by large vessels (Fig 1). A tagged red cell perfusion-imaging scan documented a $14 \%$ right-to-left shunt (normal, <5\%). Echocardiographic bubble study confirmed the shunt (Fig 2). The patient underwent uneventful VATS and wedge resection of the PAVM. Pathologic examination showed a benign PAVM. Pulmonary angiography, tagged red cell scan, and echocardiography were normal after operation (Fig 3). He continues to do well 4 months later.

Discussion. PAVMs are unusual tumors of the lung, which occur spontaneously or in diseases such as hereditary hemorrhagic telangiectasia (Osler-Weber-Rendu syndrome) or hepatic cirrhosis. ${ }^{1}$ On CT scan they are diagnosed by their large feeding vessels. ${ }^{2}$ They result in right-to-left shunting with dyspnea, fatigue, hypoxemia, and cyanosis. ${ }^{3}$ Stroke or cerebral abscess may result from paradoxic embolization.

The treatment goals are obliteration of the PAVM to resolve symptoms and prevent complications. Options for treatment include transcatheter embolization or surgical resection. Transcatheter embolization with balloons or stainless steel

From the Department of Surgery, Division of Thoracic and Cardiovascular Surgery, University of New Mexico School of Medicine, Albuquerque.

Received for publication June 15, 1998; accepted for publication July 15, 1998.

Address for reprints: R. Thomas Temes, MD, Department of Surgery, University of New Mexico, 2211 Lomas Boulevard, NE, Albuquerque, NM 87131.

J Thorac Cardiovasc Surg 1998;116:878-9

Copyright $\odot 1998$ by Mosby, Inc.

$0022-5223 / 98 \$ 5.00+0 \quad \mathbf{1 2 / 5 4 / 9 3 0 8 6}$

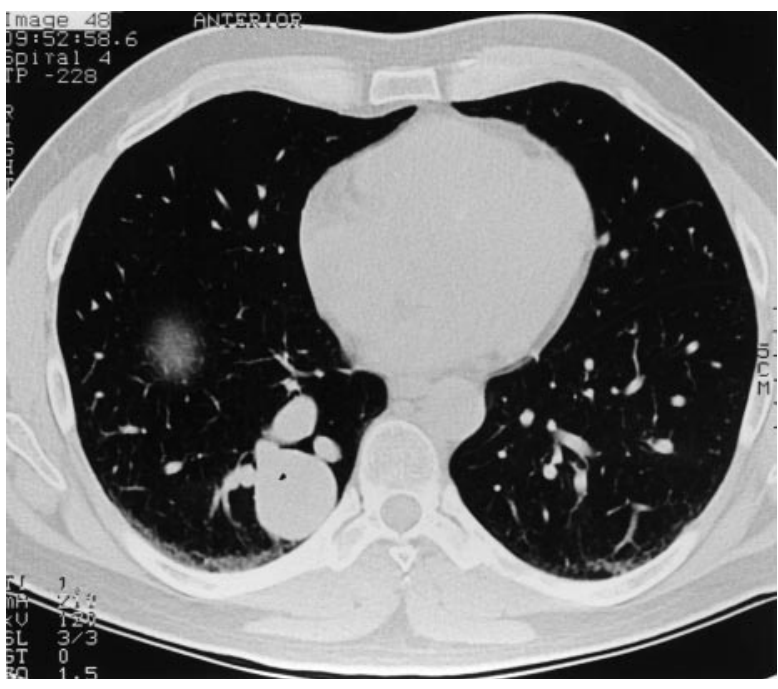

Fig 1. CT scan of chest shows a mass consistent with PAVM.

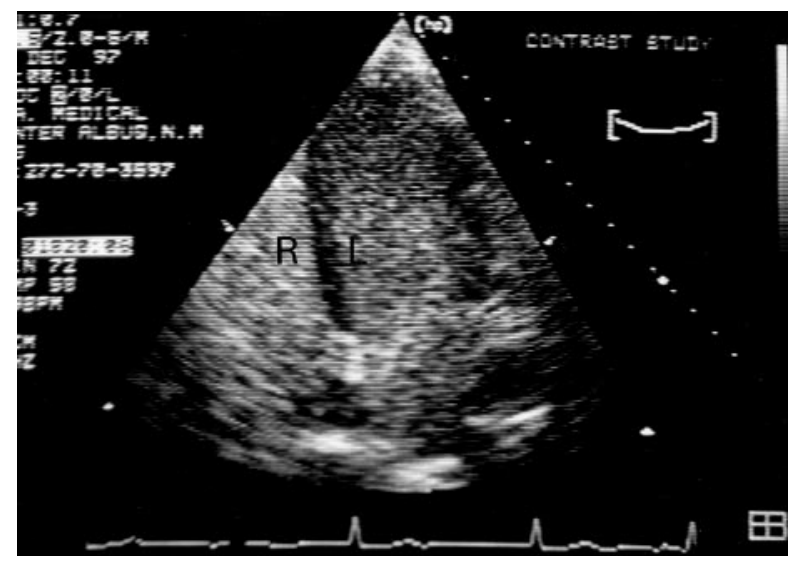

Fig 2. Preoperative echocardiographic bubble study with right-to-left shunt.

coils is clearly indicated in patients with multiple PAVMs or those unsuitable for surgical resection for other reasons. ${ }^{3}$ In patients with isolated PAVMs, the advantages of transcatheter embolization are the low procedural morbidity and mortality rates. Potential complications of embolization include air emboli, pulmonary infarction, migration of devices, and persistence or recanalization of the PAVM. ${ }^{3,4}$

Surgical resection provides definitive treatment of solitary 


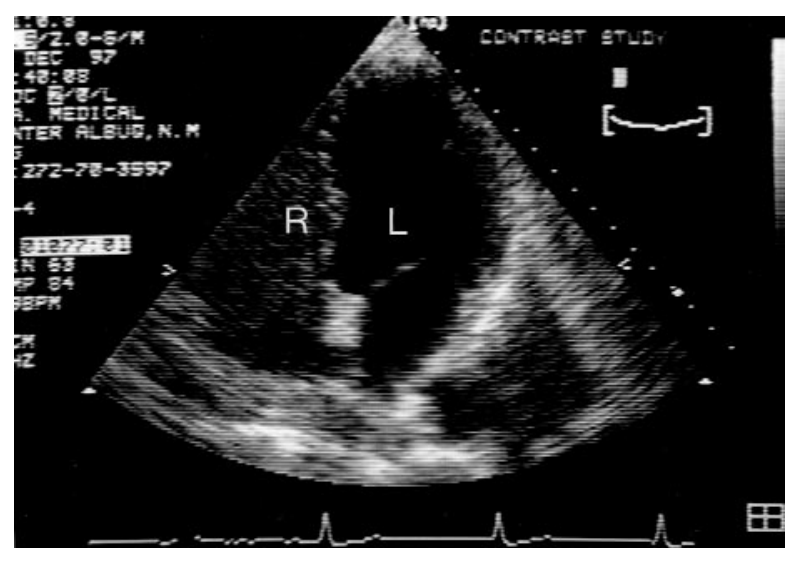

Fig 3. Preoperative echocardiography bubble study shows resolution of right-to-left shunt.

PAVMs but is performed infrequently because of the higher morbidity and mortality rates of thoracotomy. With VATS, surgical risks are minimal. VATS offers the advantages of complete surgical resection without the disadvantages of a major surgical procedure or the risks of transcatheter embolization. We report a case of successful VATS resection of an isolated PAVM. The risk-to-benefit ratio of this procedure may result in VATS becoming the treatment of choice in patients with isolated PAVM.

\section{REFERENCES}

1. Puskas JD, Allen MS, Moncure AC. Pulmonary arteriovenous malformations: therapeutic options. Ann Thorac Surg 1993;56: 253-8.

2. Bailey PV, Tracy T, Connors R. Congenital bronchopulmonary malformations: diagnostic and therapeutic considerations. J Thorac Cardiovasc Surg 1990;99:597-603.

3. Lee DW, White RI, Egglin TK. Embolotherapy of large pulmonary arteriovenous malformations: long-term results. Ann Thorac Surg 1997;64:930-40.

4. Remy-Jardin M, Wattinne L, Remy J. Transcatheter occlusion of pulmonary arterial circulation and collateral supply: failures, incidents, and complications. Radiology 1980;3: $700-5$.

\section{Availability of Journal back issues}

As a service to our subscribers, copies of back issues of The Journal of Thoracic and Cardiovascular Surgery for the preceding 5 years are maintained and are available for purchase from Mosby at a cost of $\$ 16.00$ per issue until inventory is depleted. The following quantity discounts are available: $25 \%$ off on quantities of 12 to 23, and one third off on quantities of 24 or more. Please write to Mosby, Inc, Subscription Services, 11830 Westline Industrial Drive, St Louis, MO 63146-3318, or call 800-453-4351 or 314-453-4351 for information on availability of particular issues. If unavailable from the publisher, photocopies of complete issues may be purchased from UMI, 300 N Zeeb Rd, Ann Arbor, MI 48106, 313-761-4700. 